\title{
CONFORTO AMBIENTAL EM ARQUITETURA PARA IDOSOS
}

Jessica Akemi Hayashi, Fabrícia Dias de Moraes Fernandes Borges

Universidade do Oeste Paulista - UNOESTE, curso de Arquitetura e Urbanismo, Presidente Prudente, SP. E-mail: jessicahayashii@gmail.com

\section{RESUMO}

O presente artigo tem objetivo de refletir sobre a arquitetura voltada para a vivência de uma pessoa idosa, utilizando como metodologia levantamentos bibliográficos e tendo como foco de discussão em como o conforto ambiental do lugar em que a pessoa reside pode colaborar para que a mesma possua um nível de agradabilidade elevado. Identifica-se e explana-se sobre os tipos de conforto ambiental (conforto visual, térmico e acústico) e suas características. Com a análise teórica dos dados foi possível refletir em como tais elementos auxiliam de forma subjetiva a aumentar o bem estar dos idosos, apesar das limitações e mudanças ocorridas em seu corpo, decorrente da idade avançada.

Palavras-chave: Conforto Ambiental, Conforto Térmico, Conforto Visual, Conforto Acústico, Idoso.

\section{ENVIRONMENTAL CONFORT IN ARCHITECTURE FOR ELDERLY}

\section{ABSTRACT}

The present article has the objective to begin observations about the architecture of an elderly person, using bibliographical surveys as a methodology and having as a focus of discussion how the environmental comfort of the place where the person resides can collaborate so that it has a high level of pleasantness. It identifies and explains the types of environmental comfort (visual, thermal and acoustic comfort) and their characteristics. With the theoretical analysis of the data it was possible to reflect on how these elements help in a subjective way to increase the well-being of the elderly, despite the limitations and changes that occurred in their body, due to the advanced age.

Keywords: Environmental Comfort, Thermal Comfort, Visual Comfort, Acoustic Comfort, Elderly.

\section{INTRODUÇÃO}

Segundo Hazin (2012) deve-se lembrar de que uma arquitetura destinada aos idosos deve proporcionar o acolhimento como uma das premissas básicas para a satisfação dele. Esta está ligadas ao conforto, principalmente o ambiental, representado pela qualidade da edificação e sua relação com os meios naturais, juntos proporcionam um bem-estar físico e psíquico e contribuem no comportamento do homem.

Bianchi (2013) acrescenta que as variáveis do recinto, tais como a ventilação, luz, som, calor e texturas, presentes conforto ambiental interferem na saúde do idoso, de forma direta ou indireta. A natureza é tranquilizadora, traz leveza à mente, os elementos que a compõe são agradáveis aos olhos e ao corpo também, eles instigam tanto o descanso, quanto a prazer de realizar atividades.

Albuquerque (apud HAZIN, 2012, p. 62) corrobora com os autores acima quando explica que a qualidade depende da funcionalidade física, social e psicológica do lugar e ainda afirma que "[...] A qualidade de vida na velhice possui, portanto, relações muito estreitas com as condições ambientais, que permitem aos idosos desempenharem comportamentos biológicos e psicológico- 
adaptativos", já que a identificação com o espaço proporciona o sentimento de pertencimento e, consequentemente a de segurança por estar em um lugar favorável a sua existência.

O objetivo deste estudo foi compreender os tipos de conforto ambiental (conforto visual, térmico e acústico) e sua relação com as pessoas idosas, a fim de compreender em como a arquitetura pode colaborar para a sensação de bem estar deste público.

\section{METODOLOGIA}

A metodologia seguida na pesquisa que embasa este artigo foi baseada em levantamentos bibliográficos e partiu de aprofundamento teórico e conceitual, buscando compreender o conceito do tema abordado.

\section{CONFORTO VISUAL}

Conforto visual é um estado obtido pela combinação de uma iluminação adequada com uma vista saudável. O envelhecimento causa um desgaste natural nos olhos, assim como as doenças congênitas, oriundas do uso inadequado da visão, diminuindo a capacidade visual das pessoas, agravando-se na velhice (BARBOSA, 2002).

De acordo com o Instituto Alemão de Luminotécnica (apud HAZIN, 2012), para que os idosos possam ter um rendimento e um conforto visual eficiente, recomenda-se uma iluminância maior, pouco mais do dobro da necessária para um jovem. Para uma tarefa visual que requer 100 lux, a ser realizada por um jovem de 20 anos, o idoso de 60 anos precisa aproximadamente de 200 lux. Estas diferenças, no entanto, segundo este instituto, desaparecem quando as iluminâncias são maiores.

Além de apresentarem capacidade visual inferiores do que as demais faixas etárias, as pessoas idosas exigem uma iluminação com cuidados especiais, em virtude as suas limitações físicas e perceptivas. Recomenda-se que o ambiente seja estimulante e equilibrado concomitantemente, com a presença de luz solar, plantas e cores (HAZIN, 2012).

Hazin (2012) continua sua linha de pensamento ressaltando que a luz natural pode proporcionar muitos benefícios psicológicos e fisiológicos, auxiliando o longevo a manter seu ritmo biológico ao seguir as fases dia e da mudança na paisagem, uma vez que sua percepção temporal também é reduzida.

A pessoa idosa necessita ainda de mais luminosidade para conseguir realizar suas tarefas. O contraste de cores entre os itens que constituem seus ambientes e seus mobiliários carecem de ser intensificados para que a identificação ocorra mais facilmente. No entanto o contraste e a luz devem ser moderados, pois os idosos são mais sensíveis ao ofuscamento e precisam de mais tempo para se adaptar das mudanças de luminosidade, sendo sempre interessante proporcionar uma transição gradual de luminâncias (BARBOSA, 2002).

Bianchi (2013) indica a utilização de cores suaves para compor os recintos, como por exemplo, o amarelo claro, azul e verde, uma vez que refletem de $70 \%$ a $80 \%$ da luz incidente, agregando leveza ao lugar através da atenuação da fatiga visual. Hazin (2012), além de falar sobre a importância das cores claras e utilização de texturas distintas para estimular o cérebro dos longevos, afirma ainda que eles necessitam de uma iluminação uniforme, contínua e ao mesmo tempo antiofuscante e forte.

Entende-se então que não se deve proporcionar iluminação que incida diretamente nos olhos das pessoas, seja ela natural ou artificial, isto causa desconforto e prejudica o órgão, o mais indicado é que a luminosidade seja antiofuscante, que é amplamente utilizado em corredores e espaços que não necessitam de luz forte, como é o caso de ambientes de trabalho. 


\section{CONFORTO TÉRMICO}

Conforto térmico é um estado obtido através da satisfação de determinado indivíduo em relação à sensação térmica do ambiente. "É muito difícil satisfazer a todos os usuários de um mesmo espaço devido às grandes variações fisiológicas e psicológicas existentes entre as várias pessoas de uma mesma população" (VITTORINO; AQUILINO apud HAZIN 2012).

Hazin (2012) aponta as variáveis que interferem neste tipo de conforto em um ambiente como sendo a temperatura, umidade e velocidade do ar, além da temperatura média radiante do ambiente. As outras variáveis que podem intervir são relacionadas às características do ser humano, como a idade, sexo, grau de aclimatação, tipo de vestimenta e atividade física que está sendo exercida.

Barbosa e Barroso (apud HAZIN, 2012, p. 64) explicam porque as pessoas mais velhas são mais vulneráveis às alterações de temperatura e umidade:

Com a idade, o metabolismo humano se reduz e há uma diminuição na quantidade de água nos órgãos da pele, que faz o idoso sentir mais frio do que quando jovem. Por este motivo, o idoso tem maior dificuldade em se adaptar às variações de temperatura e de perceber que seu corpo está excessivamente frio ou quente. Isso justifica as atitudes instintivas e culturais tão comuns entre os mais velhos, tais como: curvar o corpo, diminuindo a área de exposição da pele; esfregar as mãos ou colocá-las nos bolsos; usar casacos ou roupas de lã, quando aparentemente não é necessário.

O autor ainda destaca que os longevos precisam de lugares mais quentes, pois "[...] Devido a razões físicas, queda no metabolismo, perda de apetite, baixa nutrição, os idosos são incapazes de gerar calor suficiente para o corpo, e por isso sentem frio" (HAZIN, 2012, p. 64).

Bianchi (2013) sugere que para minimizar o estresse térmico e adquirir estado de conforto pode-se utilizar de uma ventilação cruzada permanente, que também irá renovar o ar, evitando assim a proliferação de bactérias em grandes quantidades. Hazin (2012) conclui ainda que ao se projetar ambientes voltados para os idosos deve-se então buscar um espaço que possibilite que o organismo se mantenha em equilíbrio térmico, deixando-o propício para as atividades a serem realizadas.

\section{CONFORTO ACÚSTICO}

Conforto acústico é um estado obtido através da sensação de bem estar em relação com o som no ambiente em que se está presente. Bianchi (2013) ressalta a sua relevância, pois se trata de um aspecto que nem sempre pode ser controlado, uma vez que é influenciado por uma série de fatores, entre eles os internos e externos ao ambiente, além das pessoas que os ocupam.

Segundo Barbosa (2002) ao longo da vida, os seres humanos perdem gradualmente parte de sua audição à medida que envelhecem, sobretudo nas frequências altas, que se referem aos sons agudos. Ao analisar a ocorrência de acordo com o sexo, constatou-se que os homens são atingidos em maior grau em comparação com as mulheres. Ademais foi averiguado que a perda da audição reflete em uma minimização na inteligibilidade da fala.

Para os idosos o conforto acústico deriva da eliminação dos ruídos não desejáveis e do equilíbrio de sons no ambiente, contribuindo assim para o seu bem-estar e para sua saúde auditiva. Para os que apresentam deficiências auditivas decorrentes do processo do envelhecimento, é primordial que se tenha uma melhora da inteligibilidade (BARBOSA, 2002).

Estratégias construtivas para a diminuição do ruído externo como a utilização de portas e janelas acústicas, uso de cortinas, colocação de lã de rocha na parede ou entre elas, diminuem a 
entrada de ruídos no recinto e o mobiliário, materiais e revestimentos que absorvem o som presentes no próprio ambiente minimizam a reverberação dos ruídos produzidos dentro dele (HAZIN, 2012). A tabela 1 apresenta os tipos de ruídos e os danos que eles podem causar.

TABELA 1- Consequências Geradas pelos Ruídos

\begin{tabular}{|l|l|l|}
\hline \multirow{2}{*}{ TIPO DE RUÍDO } & NíVEL DO RUÍDO & CONSEQUÊNCIAS \\
\hline $\begin{array}{l}\text { Grave (são os menos } \\
\text { danosos) }\end{array}$ & Baixa intensidade & Produzem uma suave fadiga. \\
\cline { 2 - 3 } & A partir dos $100 \mathrm{~dB}$ & $\begin{array}{l}\text { Podem gerar vertigens, vômitos e síncope } \\
\text { cardíaca. }\end{array}$ \\
\cline { 2 - 3 } & A partir dos $130 \mathrm{~dB}$ & $\begin{array}{l}\text { O som propagado se torna prejudicial ao } \\
\text { ouvido interno. }\end{array}$ \\
\hline $\begin{array}{l}\text { Média frequência } \\
\text { (geram os mesmos } \\
\text { efeitos acima, em níveis } \\
\text { mais intensos) }\end{array}$ & A partir dos $80 \mathrm{~dB}$ & $\begin{array}{l}\text { É possível ocorrer transtornos digestivos, } \\
\text { aumento da pressão arterial e } \\
\text { aceleramento do pulso. }\end{array}$ \\
\hline $\begin{array}{l}\text { Agudo (são os mais } \\
\text { prejudiciais) }\end{array}$ & $\begin{array}{l}\text { Estimula o sistema nervoso central, } \\
\text { ocasionando um estado de tensão com } \\
\text { sequelas de fadiga nervosa e cansaço } \\
\text { mental. }\end{array}$ \\
\hline
\end{tabular}

Fonte: Hazin (2012). Modificado: Autora (2017).

Hazin (2012) salienta que diferente das pessoas mais jovens e saudáveis, que podem se adaptar e resistir a situações de desconforto, os idosos são mais frágeis e vulneráveis aos efeitos que os ruídos são capazes de causar ao ser humano, necessitando assim de mais atenção e preocupação ao projetar recintos que recebem este público.

\section{CONCLUSÃO}

Define-se o conforto como satisfatório ou insatisfatório para a pessoa que usufrui do habitat, de acordo com a junção das variáveis dos ambientes e a sensação que elas transmitem ao usuário. As variáveis podem ser identificadas como temperatura, luminosidade, conforto acústico e conforto visual (HAZIN, 2012).

O presente artigo fornece informações para que seja possível projetar uma moradia para idosos de modo que esta possua condições de conforto ambiental satisfatório paras pessoas desta faixa etária, visando sua condição física e medidas projetuais para adequar o ambiente a ela, deste modo a pessoa idosa evita realizar esforços desnecessários que prejudiquem sua visão, audição, entre outros.

É elucidado que aspectos físicos como a iluminação, temperatura, sons, a natureza sejam eles naturais ou artificiais impostos pelo homem, influenciam diretamente no bem-estar das pessoas, sobretudo dos idosos, uma vez que este grupo tende a ser mais vulnerável as variações do ambiente.

\section{REFERÊNCIAS BIBLIOGRÁFICAS}

BIANCHI, S. A. Qualidade do Lugar nas Instituições de Longa Permanência para Idosos Contribuições Projetuais para Edificações na Cidade do Rio de Janeiro. 2013. 294f. Monografia (Especialização) - Faculdade de Arquitetura e Urbanismo, Universidade Federal do Rio de Janeiro, Rio de Janeiro, 2013. 
HAZIN, M. M. V. Os Espaços Residenciais na Percepção dos Idosos Ativos. 2012. 151f. Monografia (Especialização) - Universidade Federal de Pernambuco, Recife, 2012.

BARBOSA, A. L. G. M. Conforto e qualidade ambiental no habitat do idoso. 2002. 136 f. Dissertação (Mestrado em Arquitetura), Universidade Federal do Rio de Janeiro, Rio de Janeiro, 2002. 